\title{
Damaged Orthotropic Failure Surface for Masonry Walls
}

\author{
Amr G. Abdellah ${ }^{1}$, Salah E. El-Metwally ${ }^{2}$, Ahmed M. Yousef ${ }^{3}$ \\ ${ }^{1}$ Assistant Lecturer, Housing and Building Research Center, Cairo, Egypt \\ ${ }^{2,3}$ Professor of Structural Concrete, Mansoura University, El-Mansoura, Egypt
}

\begin{abstract}
Though they are naturally anisotropic and heterogeneous, the mechanical behavior of masonry walls in the micro modeling for the purpose of nonlinear analysis, can be simplified by adopting the homogenization technique. In this, the Cartesian coordinates coincide with the bed joint and in perpendicular (in the direction of the head joint); then, the wall is treated as an orthotropic material. In this paper, the development of a ten parameters failure criterion is presented; where the parameters are obtained from experimental tests. The tests of Page are used to show how the procedure of regression analysis can be performed for a better prediction of the wall strength. The obtained results show the effectiveness of the homogenization technique and the reliability of the proposed regression procedure in the development of the failure surface. The proposed failure criterion allows the use of continuum damage mechanics and the incremental approach for tension and compression regimes by inserting damage variables to the criterion. The proposed failure surface and preliminary results show the potential of modeling masonry under biaxial state of stress.
\end{abstract}

Keywords: Masonry walls; Failure criterion (surface); orthotropic material; plane stress; damage; regression analysis.

\section{INTRODUCTION}

The mechanical behavior of masonry walls in structures has been a focus of interest in the last decades. Masonry is a composite anisotropic material with different directional properties as a result of its constituent components; e.g., bricks and mortar joints. For the nonlinear analysis of masonry walls, which are anisotropic, with the aid of the Finite Element Method, there are two concepts; the homogenized and the discrete formulations. In the latter, the bricks and joints, which represent lines of weakness in the wall, are discretized and hence the mesh is complex, which 
demands excessive computation effort. This approach is referred to as the micro modeling. In order to overcome the disadvantages of a detailed discretized modeling a homogenization of the brick/mortar assemblage can be performed, obtaining a good correlation between experimental and numerical curves. In this approach, the Cartesian coordinates coincide with the bed joint and in perpendicular (in the direction of the head joint). The effectiveness of such a technique has been demonstrated by several authors such as Lopez et al. (1999), Anthoine (1995), and Sacco (2009). This approach is referred to as the macro modeling, which is adopted here.

In the current research the homogenization technique is adopted, which means that the overall behavior of the masonry panel will be evaluated. Suquet (1985) defined the homogenization technique as: "the procedure of replacing a strongly heterogeneous material by a homogenous material similar to the previous one within the normal range". Unlike a micro-model where bricks and mortar are separately modeled a homogenized model represents an efficient method to predict the overall nonlinear behavior of the masonry panel.

In the homogenization technique a periodic unit cell is identified so that its repetition generates an entire masonry panel and its behavior is analyzed as an individual problem in such a way to know the average values of the masonry panel as a single homogeneous material based on the actual geometrical and mechanical characteristics of the constituent material (Quinteros, et al., 2012). In addition, a periodic unit cell could be used as well to perform a limit analysis for the prediction of collapse loads and homogenized failure mechanisms, such as Milani (2010), Milani and Bucchi (2010) and Milani et al. (2010) modelling bricks, joints, filling resin and glass fiber reinforced polymer rods for out-of-plane step loads.

For understanding the mechanical behavior of masonry walls and for performing a nonlinear structural analysis, the failure criterion of the material is the key. In the case of masonry walls the uncertainty associated with the mechanical properties represents a major challenge.

In this paper, a failure criterion is developed for masonry walls in which the homogenization concept is adopted. Nevertheless, the wall is treated as an orthotropic material where the properties of the wall is considered uniform in the bed direction and in the direction perpendicular to the bed. The wall is treated as a plane stress problem with the properties of the wall uniform through its thickness.

\section{MODEL DEVELOPMENT}

\subsection{Background}

The experimental work of Page (1981) on masonry formed the foundation for many researchers to verify their work. The orientation of the bed joint to the applied principal stress was found to influence the failure pattern only in those cases in which one principal stress was dominant. In all his tests, he used half-scale brick masonry. The bed joints inclination to the principal stresses was studied under different angels; $0^{\circ}, 22.5^{\circ}, 45^{\circ}, 67.5^{\circ}$, and $90^{\circ}$, Fig. 1 . 


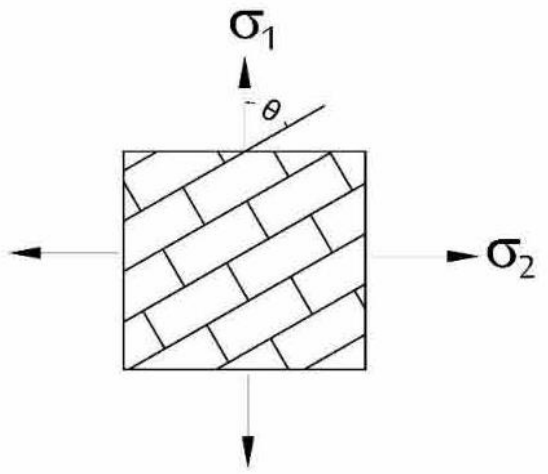

(a) Biaxial test

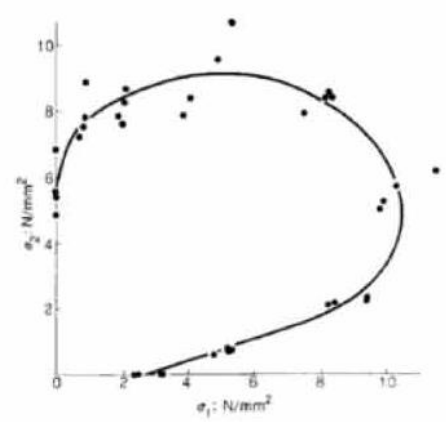

(c) Failure of Brickwork under biaxial compression, $\theta=22.5$

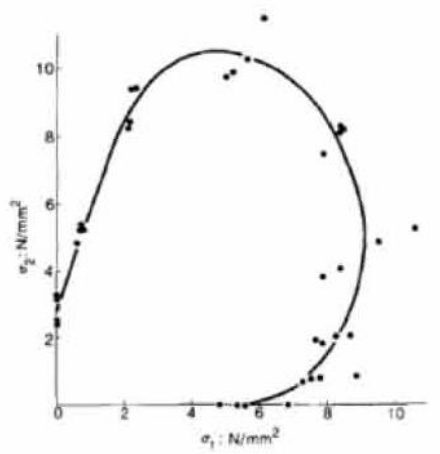

(e) Failure of Brickwork under biaxial compression, $\theta=67.5$

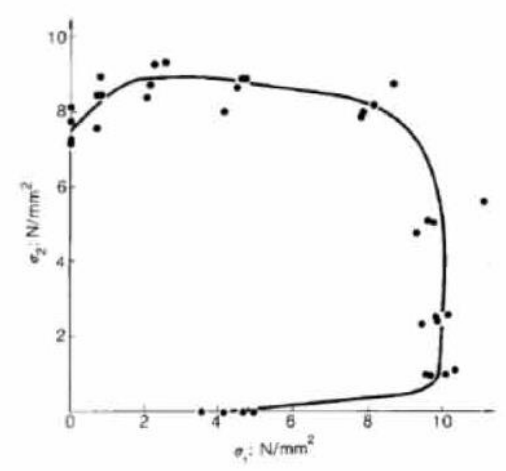

(b) Failure of Brickwork under biaxial compression, $\theta=0^{\circ}$

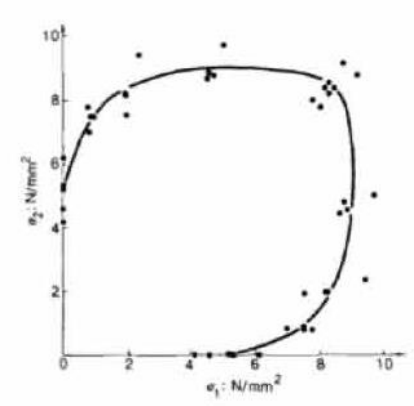

(d) Failure of Brickwork under biaxial compression, $\theta=45$

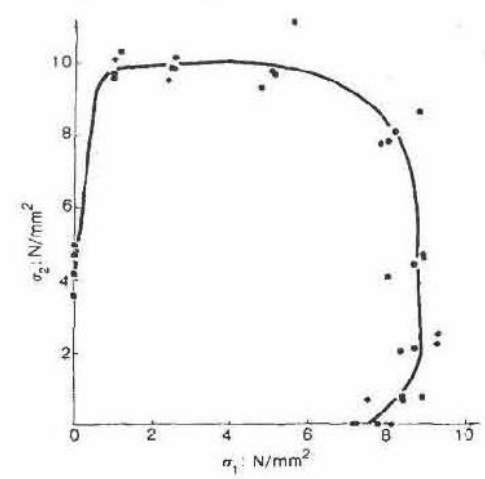

(f) Failure of Brickwork under biaxial compression, $\theta=90$

Figure 1 Failure of brickwork under biaxial compression by Page (1981).

Dhanasekar et al. (1985) proposed the following failure surface using a quadratic polynomial from Page's experiments.

$\mathrm{f}\left(\sigma_{1}\right)=A \sigma_{n}^{2}+B \sigma_{p}^{2}+C \tau^{2}+D \sigma_{n} \sigma_{p}+E \sigma_{n}+\mathrm{F} \sigma_{p}-1=0$

The constants A, B, C, D, E, F define the elliptical cone proposed by Dhanasekar, and are evaluated so that if the stress point lies outside the failure surface the left hand side of Eq. (1) is negative. The subscripts $n$ and $p$ of the stress $\sigma$ stand for the stresses normal and parallel to the bed joints and $\tau$ is the shear stress. 
The principal stress directions of the test data were transformed into normal and parallel to the direction of the bed joint. A reasonable approximation was achieved in a comparison with the test data. According to the author, inconsistencies took place in the corner of the plots.

Lourenco (1995 and 1998) proposed an isotropic continuum model, where a Hill yield criterion was used in compression and a Rankine yield criterion in tension, Fig. 2.

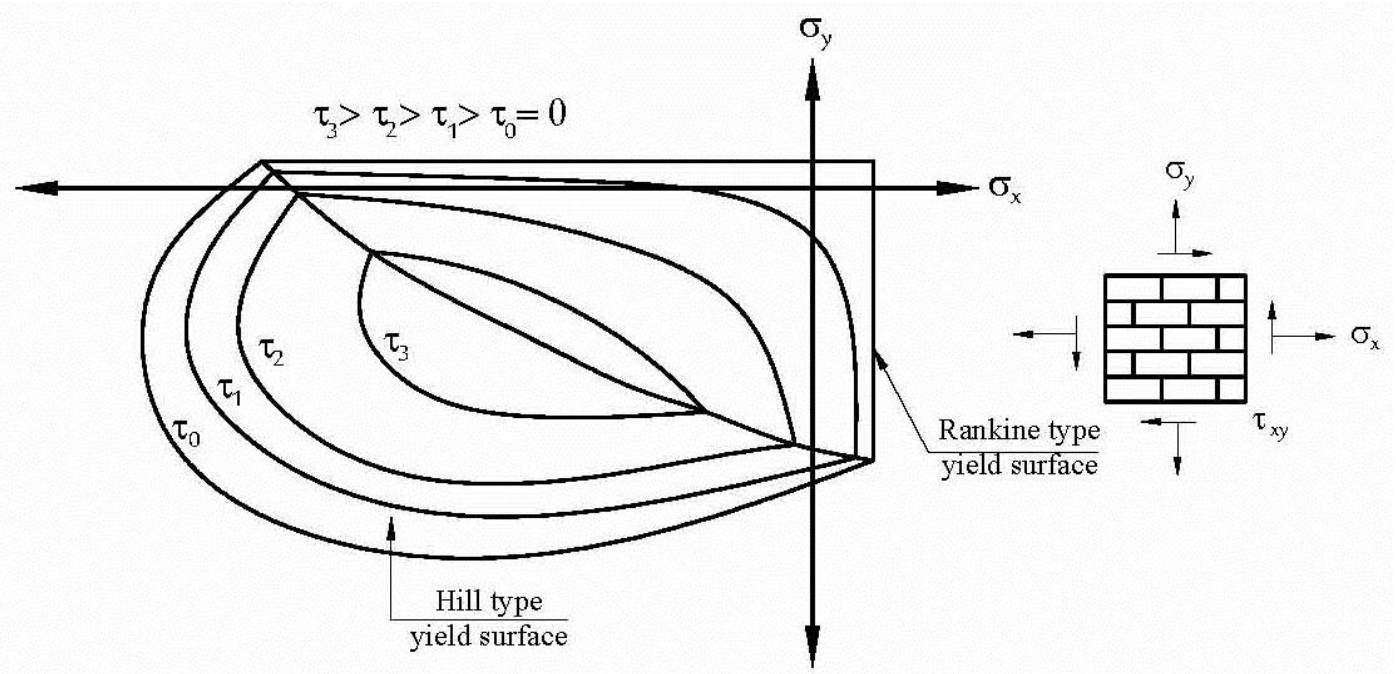

Figure 2 Lourenco's composite yield surface (Lourenco, 1995 and 1998).

Syrmakezis and Asteris (2001) also described the failure surface using a cubic polynomial to describe both tension and compression regimes in a masonry panel. The directions of the tests were transformed this time to the $\mathrm{x}$ - and $\mathrm{y}$-directions. The equation obtained by the authors showed better compliance with the test data and also at the corners of the plots. The cubic polynomial is a better approximation than the quadratic polynomial.

\subsection{Basic Conditions}

A failure surface should satisfy the following conditions:

- It has to be a closed surface;

- For stability it should have a convex shape (Hill, 1950, and Prager, 1959);

- It should satisfy uniqueness; and

- The computation of singular points "corners" on failure surface has to be avoided by a suitable choice of a continuous surface (Zienkiewics et al., 1969).

These conditions are considered in the following development for a plane stress orthotropic failure surface.

\subsection{Mathematical formulation}

The most general failure criterion available for anisotropic material is the tensor polynomial. Tsai and $\mathrm{Wu}(1971)$ proposed a cubic polynomial as a failure criterion 
for anisotropic composite materials. The general equation for a cubic polynomial is given by Eq. (2),

$\mathrm{f}\left(\sigma_{\ell}\right)=\mathrm{a}_{\mathrm{i}} \sigma_{\mathrm{i}}+\mathrm{a}_{\mathrm{ij}} \sigma_{\mathrm{i}} \sigma_{\mathrm{j}}+\mathrm{a}_{\mathrm{ijk}} \sigma_{\mathrm{i}} \sigma_{\mathrm{j}} \sigma_{\mathrm{k}}+\cdots-1=0$

where $\ell=1,2, \ldots, 6, \mathrm{i}, \mathrm{j}$ and $\mathrm{k}$ designate $1,2, \ldots, 6$. The $\mathrm{a}_{\mathrm{i}}, \mathrm{a}_{\mathrm{ij}}$ and $\mathrm{a}_{\mathrm{ijk}}$ are material property coefficients. This polynomial has been the base for models applicable to masonry walls for decades.

Eq. (2) can be simplified for the case of plane stress and considering that a cubic formulation is adequate to represent the failure surface (Syrmakezis and Asteris, 2001), as given by Eq. (3),

$$
\begin{aligned}
\mathrm{f}\left(\sigma_{\ell}\right)=\mathrm{a}_{1} \sigma_{1} & +\mathrm{a}_{2} \sigma_{2}+\mathrm{a}_{6} \sigma_{6}+a_{11} \sigma_{1}^{2}+\mathrm{a}_{12} \sigma_{1} \sigma_{2}+\mathrm{a}_{16} \sigma_{1} \sigma_{6} \\
& +a_{22} \sigma_{2}^{2}+\mathrm{a}_{26} \sigma_{2} \sigma_{6}+\mathrm{a}_{21} \sigma_{2} \sigma_{1}+a_{66} \sigma_{6}^{2}+\mathrm{a}_{61} \sigma_{6} \sigma_{1} \\
& +\mathrm{a}_{62} \sigma_{6} \sigma_{2}+\mathrm{a}_{111} \sigma_{1}^{3}+a_{112} \sigma_{1}^{2} \sigma_{2}+a_{116} \sigma_{1}^{2} \sigma_{6}+a_{121} \sigma_{1}^{2} \sigma_{2} \\
& +a_{122} \sigma_{1} \sigma_{2}^{2}+a_{126} \sigma_{1} \sigma_{2} \sigma_{6}+a_{161} \sigma_{1}^{2} \sigma_{6}+a_{162} \sigma_{1} \sigma_{2} \sigma_{6} \\
& +a_{166} \sigma_{1} \sigma_{6}^{2}+a_{211} \sigma_{1}^{2} \sigma_{2}+a_{222} \sigma_{2}^{3}+a_{212} \sigma_{1} \sigma_{2}^{2} \\
& +a_{216} \sigma_{1} \sigma_{2} \sigma_{6}+a_{221} \sigma_{1} \sigma_{2}^{2}+a_{226} \sigma_{2}^{2} \sigma_{6}+a_{261} \sigma_{1} \sigma_{2} \sigma_{6} \\
& +a_{262} \sigma_{2}^{2} \sigma_{6}+a_{266} \sigma_{2} \sigma_{6}^{2}+a_{611} \sigma_{1}^{2} \sigma_{6}+a_{612} \sigma_{1} \sigma_{2} \sigma_{6} \\
& +a_{616} \sigma_{1} \sigma_{6}^{2}+a_{621} \sigma_{1} \sigma_{2} \sigma_{6}+a_{622} \sigma_{2}^{2} \sigma_{6}+a_{626} \sigma_{2} \sigma_{6}^{2} \\
& +a_{661} \sigma_{1} \sigma_{6}^{2}+a_{662} \sigma_{2} \sigma_{6}^{2}+a_{666} \sigma_{6}^{3}-1=0
\end{aligned}
$$

Upon considering the bed direction as the $\mathrm{x}$-axis, the normal to the bed as the $y$-axis and the out of plane as the z-axis; thus, the material representing the wall is assumed to be isotropic in the positive $\mathrm{x}$ - and y-directions. Then, the following can be assumed,

- For plane stress state $\left(\sigma_{\mathrm{z}}=\tau_{\mathrm{xz}}=\tau_{\mathrm{yz}}=0\right)$;

- Since the material is isotropic in every respective direction, $x-, y-$ and zdirection, symmetry leads to $\left(a_{i j k}=a_{i k j}=a_{j i k}=a_{k i j}=a_{k j i}\right.$ and $\left.a_{i j}=a_{j i}\right)$;

- The material under given shear loading possesses a common shear strength for both positive and negative direction of shear loading. Therefore, all terms containing $\tau_{\mathrm{xy}}$ and $\left(\tau_{\mathrm{xy}}\right)^{3}$ will be excluded from the equation; and

- Furthermore the redundant terms $\left(\sigma_{\mathrm{x}}\right)^{3}$ and $\left(\sigma_{\mathrm{y}}\right)^{3}$ are neglected.

Syrmakezis and Asteris (2001) implemented the aforementioned assumptions into Eq. (3), reducing the equation to the following cubic polynomial in $\sigma_{x}, \sigma_{y}$ and $\tau_{x y}$.

2. $f\left(\sigma_{x}, \sigma_{y}, \tau_{x y}\right)=a_{1} \sigma_{x}+a_{2} \sigma_{y}+a_{3} \sigma_{x}^{2}+a_{4} \sigma_{y}^{2}+a_{5} \tau_{x y}^{2}+a_{6} \sigma_{x} \sigma_{y}+$ $a_{7} \sigma_{x} \sigma_{y}^{2}+a_{8} \sigma_{x}^{2} \sigma_{y}+a_{9} \sigma_{x} \tau_{x y}^{2}+a_{10} \sigma_{y} \tau_{x y}^{2}-1=0$

(4)

Eq. (4) was found by Syrmakezis and Asteris (2001) to fit reasonably well Page tests (Page, 1981).

\section{EVALUATION OF THE MODEL PARAMETERS FROM TESTS 3.1 Approach}

The ten parameter model failure criterion in Eq. (4) requires 10 tests at least in order to estimate the parameters. These tests should include all the possible cases of stress combinations; axial tension (compression) in the two directions, pure shear and combinations of the three stress components. As a result of the variability of the 
strength of masonry walls ten tests will not reflect the average properties of the wall unit. Hence, the number of tests is expected to be much larger than 10 and hence a regression analysis will be an essential procedure for the evaluation of the model parameters.

Upon substitution with the results of every test, $\sigma_{x}, \sigma_{y}$ and $\tau_{x y}$, a number of equations equal to the number of tests can be obtained. Since the number of equations will exceed the number of unknowns, model parameters, no unique solution can be derived. The deviation of the value of the function $f\left(\sigma_{x}, \sigma_{y}, \tau_{x y}\right)$, Eq. (4), from zero, upon substitution of any test results, represents an error. The solution obtained from regression analysis for the model parameters, $a_{1}, a_{2}, \ldots a_{10}$, is based on the minimization of the sum of squares of errors.

\subsection{Regression based on prescribed boundary conditions}

Regression analysis aiming to determine that many unknowns, ten in this case, with a large number of test data is unlikely to result in accurate estimates of these unknowns. Therefore, boundary conditions of the five mono-axial tests will be introduced separately leading to the determination of five unknowns; hence, the failure surface is enforced to go through these points.

The mono-axial tests represent the boundary conditions and these are:

i. Pure compression in the $\mathrm{x}$ - and $\mathrm{y}$-directions;

ii. Pure tension in the $\mathrm{x}$ - and $\mathrm{y}$-directions; and

iii. Pure shear.

Upon introducing the results of the five mono-axial tests, the five constants $a_{1}, a_{2}, a_{3}, a_{4}$ and $a_{5}$ can be calculated. The values of any test of the mono-axial tests, introduced into the calculations of these constants represent the average of the measured values of this test. These average values from Page tests are shown in table 1 ; in this case these values are the average of 4 sets of measurements. The other constants, $\mathrm{a}_{6}$ to $\mathrm{a}_{10}$, will be derived from regression analysis of the other test data.

In order to describe the orthotropic material behavior in continuum damage mechanics, with the adoption of homogenization, a closed failure surface is crucial. According to Tsai and $\mathrm{Wu}$ (1971), this condition is satisfied if the total Gaussian curvature $\mathrm{K}$ is positive.

$K=-\frac{1}{\left(\frac{\partial f}{\partial \sigma_{x}}\right)^{2}+\left(\frac{\partial f}{\partial \sigma_{y}}\right)^{2}+\left(\frac{\partial f}{\partial \tau_{x y}}\right)^{2}} D$

Therefore,

$$
D=\left|\begin{array}{cccc}
\frac{\partial^{2} f}{\left(\partial \sigma_{x}\right)^{2}} & \frac{\partial^{2} f}{\partial \sigma_{x} \partial \sigma_{y}} & \frac{\partial^{2} f}{\partial \sigma_{x} \partial \tau_{x y}} & \frac{\partial f}{\partial \sigma_{x}} \\
\frac{\partial^{2} f}{\partial \sigma_{x} \partial \sigma_{y}} & \frac{\partial^{2} f}{\left.\partial \sigma_{y}\right)^{2}} & \frac{\partial^{2} f}{\partial \sigma_{y} \partial \tau_{x y}} & \frac{\partial f}{\partial \sigma_{y}} \\
\frac{\partial^{2} f}{\partial \sigma_{x} \partial \tau_{x y}} & \frac{\partial^{2} f}{\partial \sigma_{y} \partial \tau_{x y}} & \frac{\partial^{2} f}{\left(\partial \sigma_{\tau_{x y}}\right)^{2}} & \frac{\partial f}{\partial \tau_{x y}} \\
\frac{\partial f}{\partial \sigma_{x}} & \frac{\partial f}{\partial \sigma_{y}} & \frac{\partial f}{\partial \tau_{x y}} & 0
\end{array}\right|<0 ;
$$


The constant $\mathrm{a}_{6}$ has to fulfill the condition $\left(-\sqrt{a_{3} a_{4}}<\frac{a_{6}}{2}<\sqrt{a_{3} a_{4}}\right)$ in order to ensure convexity, and in the same time results in the minimum sum of squares. Therefore, the value $a_{6}$ should accordingly be selected within the mentioned range.

\section{EVALUATION OF THE MODEL PARAMETERS OF PAGE TESTS 4.1 Transformation of the test data to Cartesian coordinates.} In the following, a methodology for the calculation of the failure surface using the data released by Page (1981) is illustrated. Page (1981) tests were performed in the principal axes directions, Fig. 1. However, the weak lines in a masonry panel are the vertical and horizontal mortar joints. This explains the staggered type failure in biaxial loading and in general the failure in these lines. As stated before, the bed direction is assigned the $\mathrm{x}$-axis, the normal to the bed is assigned the $\mathrm{y}$-axis and the out of plane is the z-axis. Damage defined in the $\mathrm{x}$ - and $\mathrm{y}$-directions incorporates tensile and compression failure in addition to sliding shear failure, which represents the most common types of failure in masonry.

In order to develop an expression in the $\sigma_{x^{-}} \sigma_{y^{-}} \tau_{x y}$ space, all tests performed by Page (1981) are first transferred into the Cartesian coordinates; the x-y plane. It is noted that the points on the curves with $\theta=22.5^{\circ}, 45^{\circ}, 67.5^{\circ}$ do not have the same $\tau_{x y}$; hence, they are not in the same plane. In Fig. 3 the tests of Page are plotted with reference to the principal axes and in Fig. 4 these data are transferred into the $\sigma_{x}-\sigma_{y}-\tau_{x y}$ space.

\subsection{Evaluation of the equation constants}

In order to determine the constant terms $a_{1}$ to $a_{5}$ the boundary conditions from mono-axial tests are used. The boundary conditions for Page mono-axial tests, calculated as the average of the measured results, are given in table 1 . It is to be noted that, due to the lack of tension tests for the angles $\theta=22.5^{\circ}, 45^{\circ}$ and $67.5^{\circ}$ the tensile behavior is approximated according to Samarasinghe et al. (1980). The tension tests were taken according to Page at $\theta=0$ and the other angels are approximated according to the variation of the tensile failure criterion for each angle as shown in Fig. 5. 
$\begin{array}{llllllll}\sigma_{2} & {\left[\mathrm{~N} / \mathrm{mm}^{2}\right]}\end{array}$

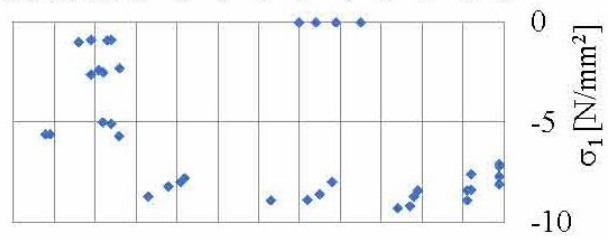

(a) Failure Points at $\theta=0^{\circ} /$ Principal $\sigma_{2}\left[\mathrm{~N} / \mathrm{mm}^{2}\right]$ $-13-12-11-10-9-8$ - $-7 \begin{array}{lllllll}-6 & -5 & -4 & -3 & -2 & -1 & 0\end{array}$

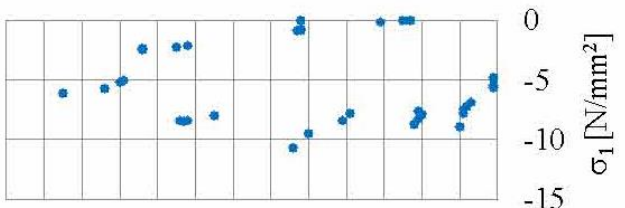

(b) Failure Points at $\theta=22^{\circ} /$ Principal

$$
\sigma_{2}\left[\mathrm{~N} / \mathrm{mm}^{2}\right]
$$

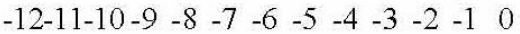

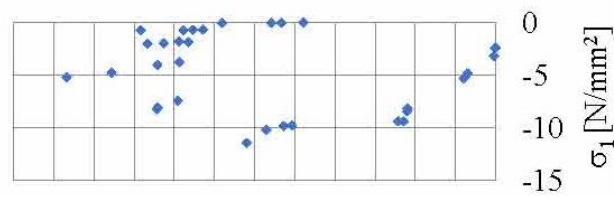

(c) Failure Points at $\theta=45^{\circ} /$ Principal

$$
\sigma_{2}\left[\mathrm{~N} / \mathrm{mm}^{2}\right]
$$

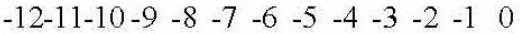

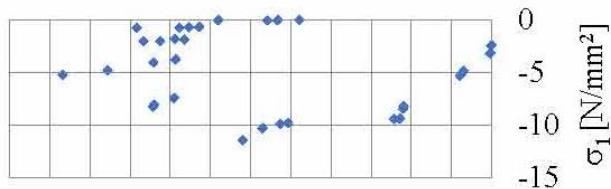

(d) Failure Points at $\theta=67.5^{\circ} /$ Principal

$$
\sigma_{2}\left[\mathrm{~N} / \mathrm{mm}^{2}\right]
$$

$\begin{array}{lllllllllll}-10 & -9 & -8 & -7 & -6 & -5 & -4 & -3 & -2 & -1 & 0\end{array}$

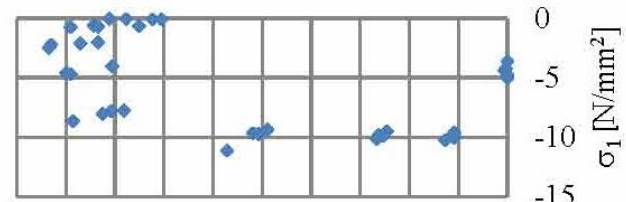

$-15$

(e) Failure Points at $\theta=90^{\circ} /$ Principal $\begin{array}{lllllll}\sigma & \sigma \times & {\left[\mathrm{N} / \mathrm{mm}^{2}\right]}\end{array}$

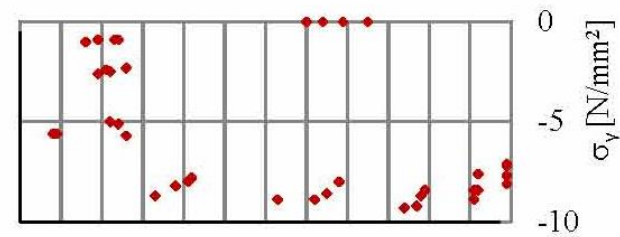

(a) Failure Points at $\theta=0^{\circ} /$ Cartesian $\mathrm{s}_{\mathrm{x}}\left[\mathrm{N} / \mathrm{mm}^{2}\right]$

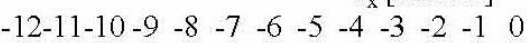

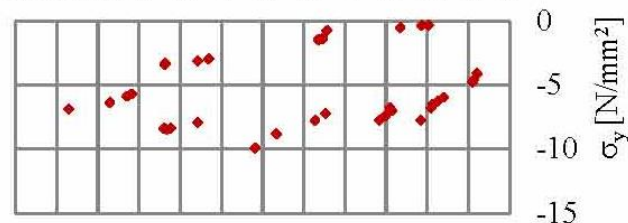

$-15$

(b) Failure Points at $\theta=22^{\circ} /$ Cartesian

$$
\sigma_{\mathrm{x}}\left[\mathrm{N} / \mathrm{mm}^{2}\right]
$$

$\begin{array}{lllllllllll}-10 & -9 & -8 & -7 & -6 & -5 & -4 & -3 & -2 & -1 & 0\end{array}$

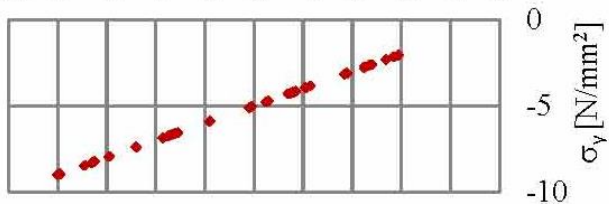

$-10$

(c) Failure Points at $\theta=45^{\circ} /$ Cartesian

$$
\sigma_{\mathrm{x}}\left[\mathrm{N} / \mathrm{mm}^{2}\right]
$$

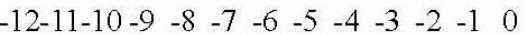

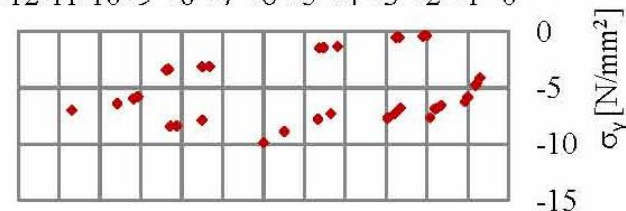

(d) Failure Points at $\theta=67.5^{\circ} /$ Cartesian

$\sigma_{\mathrm{x}}\left[\mathrm{N} / \mathrm{mm}^{2}\right]$

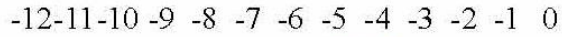

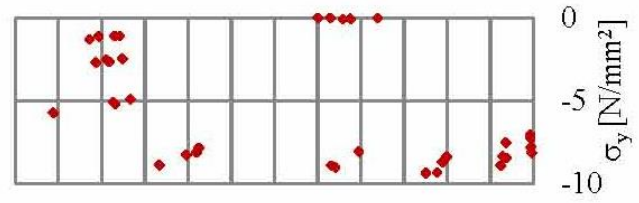

(e) Failure Points at $\theta=90^{\circ} /$ Cartesian

4. Figure 4 Failure points (Page tests) / Cartesian. 


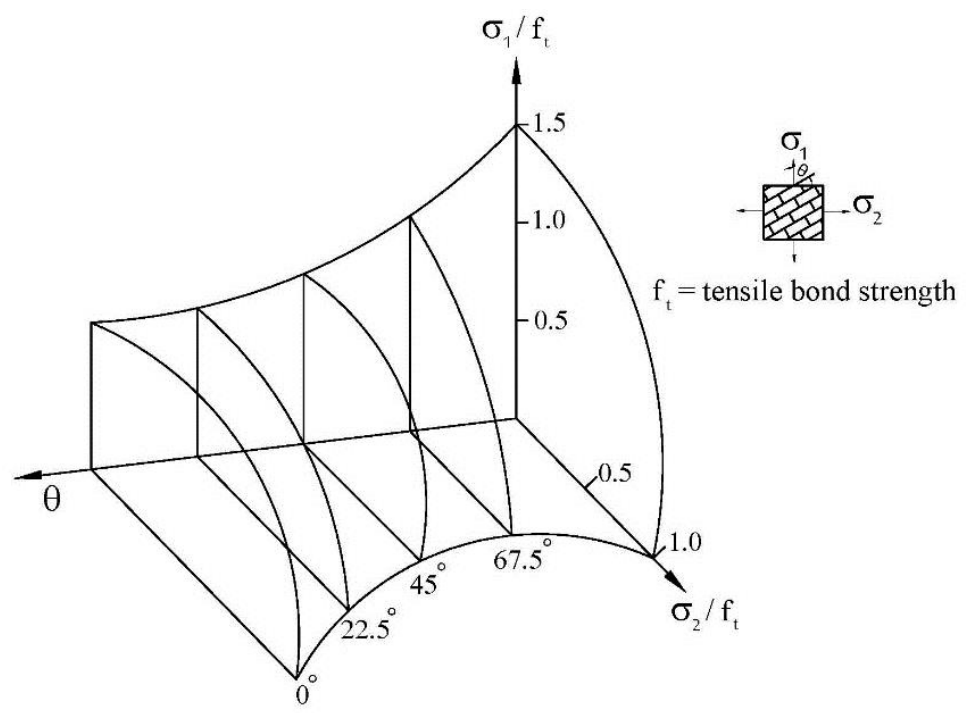

5. Figure 5 Tension failure criterion according to Samarasinghe et al. (1980).

From the boundary conditions in table 1 of Page's mono-axial tests the first five constants $\mathrm{a}_{1}$ to $\mathrm{a}_{5}$ are calculated.

$\mathrm{a}_{1}=2.271, \mathrm{a}_{2}=9.868, \mathrm{a}_{3}=0.573, \mathrm{a}_{4}=1.324$ and $\mathrm{a}_{5}=6.25$.

Then, the constant $\mathrm{a}_{6}$ should be assumed as explained in the previous section. For the failure surface to be closed and convex, the constant $a_{6}$ is selected to be $a_{6}=-0.6$ which results in the least sum of squares. Afterwards, regression on Page's test data should be performed in order to determine the other constants.

6. Table 1 - Boundary conditions for Page (1981) mono-axial tests

\begin{tabular}{|c|c|c|c|}
\hline \multirow{2}{*}{ Constant } & \multicolumn{3}{|c|}{ Uniaxial and Pure Shear Tests } \\
\cline { 2 - 4 } & $\sigma_{\mathbf{x}}$ & $\sigma_{\mathbf{y}}$ & $\tau_{\mathbf{x y}}$ \\
\hline $\mathrm{a}_{1}$ & -4.3 & 0 & 0 \\
\hline $\mathrm{a}_{2}$ & 0.4 & 0 & 0 \\
\hline $\mathrm{a}_{3}$ & 0 & -7.55 & 0 \\
\hline $\mathrm{a}_{4}$ & 0 & 0.1 & 0 \\
\hline $\mathrm{a}_{5}$ & 0 & 0 & 0.4 \\
\hline
\end{tabular}

The total number of Page's tests is 186 for the different angels as shown in Figs. 3 and 4. Regression analysis is sensitive to the choice of data; therefore, three approaches have been followed in order to determine the appropriate procedure for performing regression. In the first approach, regression was carried out using the 186 tests at once. In the second approach, for each set of tests (load combination and inclination angle) the average values were calculated making 52 data point on the surface representing the average of all sets of experiments, and these data points were used. This second approach was found to give better fit of the tests since numerical errors are significantly reduced. 
In the third approach, it was found efficient to separately perform regression on the curve for the results of each inclination angle $\theta$ of Page's experimental tests. Then, from each curve of such angle 9 points are generated and then transformed into the $\sigma_{x}, \sigma_{y}, \tau_{x y}$ space. From the regression of the points of the five angles, the 45 points in table 2 , the remaining four constants of the global equation are evaluated.

Table 2 - 45 Points used in Regression calculated from fitted equations

\begin{tabular}{|c|c|c|c|c|c|}
\hline$\sigma_{1}$ & $\sigma_{2}$ & $\theta$ & $\tau_{x y}$ & $\sigma_{x}$ & $\sigma_{y}$ \\
\hline 0.000 & -7.550 & 0 & 0.00 & 0.00 & -7.55 \\
\hline-1.000 & -8.151 & 0 & 0.00 & -1.00 & -8.15 \\
\hline-2.500 & -8.699 & 0 & 0.00 & -2.50 & -8.70 \\
\hline-5.000 & -8.919 & 0 & 0.00 & -5.00 & -8.92 \\
\hline-8.000 & -8.189 & 0 & 0.00 & -8.00 & -8.19 \\
\hline-10.850 & -5.542 & 0 & 0.00 & -10.85 & -5.54 \\
\hline-10.000 & -2.568 & 0 & 0.00 & -10.00 & -2.57 \\
\hline-7.500 & -0.959 & 0 & 0.00 & -7.50 & -0.96 \\
\hline-4.300 & 0.000 & 0 & 0.00 & -4.30 & 0.00 \\
\hline 0.000 & -5.400 & 22.5 & 1.91 & -0.79 & -4.61 \\
\hline-1.000 & -6.782 & 22.5 & 2.04 & -1.85 & -5.94 \\
\hline-2.000 & -7.659 & 22.5 & 2.00 & -2.83 & -6.83 \\
\hline-4.500 & -8.778 & 22.5 & 1.51 & -5.13 & -8.15 \\
\hline-8.500 & -8.642 & 22.5 & 0.05 & -8.52 & -8.62 \\
\hline-10.000 & -5.153 & 22.5 & -1.71 & -9.29 & -5.86 \\
\hline-8.000 & -2.810 & 22.5 & -1.83 & -7.24 & -3.57 \\
\hline-5.000 & -0.770 & 22.5 & -1.50 & -4.38 & -1.39 \\
\hline-3.300 & 0.000 & 22.5 & -1.17 & -2.82 & -0.48 \\
\hline-5.200 & 0.000 & 45 & -2.60 & -2.60 & -2.60 \\
\hline-7.000 & -1.155 & 45 & -2.92 & -4.08 & -4.08 \\
\hline-8.000 & -2.111 & 45 & -2.94 & -5.06 & -5.06 \\
\hline-9.400 & -4.585 & 45 & -2.41 & -6.99 & -6.99 \\
\hline-8.500 & -8.421 & 45 & -0.04 & -8.46 & -8.46 \\
\hline-5.000 & -9.397 & 45 & 2.20 & -7.20 & -7.20 \\
\hline-2.000 & -7.849 & 45 & 2.92 & -4.92 & -4.92 \\
\hline-1.000 & -6.779 & 45 & 2.89 & -3.89 & -3.89 \\
\hline 0.000 & -5.200 & 45 & 2.60 & -2.60 & -2.60 \\
\hline-5.600 & 0.000 & 67.5 & -1.98 & -0.82 & -4.78 \\
\hline-7.500 & -1.041 & 67.5 & -2.28 & -1.99 & -6.55 \\
\hline-8.500 & -2.123 & 67.5 & -2.25 & -3.06 & -7.57 \\
\hline-9.300 & -4.800 & 67.5 & -1.59 & -5.46 & -8.64 \\
\hline-8.500 & -8.541 & 67.5 & 0.01 & -8.53 & -8.51 \\
\hline-5.500 & -10.651 & 67.5 & 1.82 & -9.90 & -6.25 \\
\hline-2.500 & -8.145 & 67.5 & 2.00 & -7.32 & -3.33 \\
\hline-1.000 & -6.466 & 67.5 & 1.93 & -5.67 & -1.80 \\
\hline 0.000 & -2.800 & 67.5 & 0.99 & -2.39 & -0.41 \\
\hline-7.550 & 0.000 & 90 & 0.00 & 0.00 & -7.55 \\
\hline-8.000 & -0.690 & 90 & 0.00 & -0.69 & -8.00 \\
\hline-8.700 & -2.330 & 90 & 0.00 & -2.33 & -8.70 \\
\hline-9.000 & -4.200 & 90 & 0.00 & -4.20 & -9.00 \\
\hline-8.000 & -8.413 & 90 & 0.00 & -8.41 & -8.00 \\
\hline-5.500 & -10.680 & 90 & 0.00 & -10.68 & -5.50 \\
\hline-2.500 & -9.742 & 90 & 0.00 & -9.74 & -2.50 \\
\hline-1.000 & -7.468 & 90 & 0.00 & -7.47 & -1.00 \\
\hline 0.000 & -4.300 & 90 & 0.00 & -4.30 & 0.00 \\
\hline
\end{tabular}


Regression is performed as stated by the third approach, 45 points, leading to the following proposed equation,

$2.271 \sigma_{x}+9.868 \sigma_{y}+0.573 \sigma_{x}^{2}+1.324 \sigma_{y}^{2}+6.25 \tau_{x y}^{2}-0.6 \sigma_{x} \sigma_{y}-0.0136 \sigma_{x} \sigma_{y}^{2}-$
$0.0077 \sigma_{x}^{2} \sigma_{y}+0.268 \sigma_{x} \tau_{x y}^{2}+0.328 \sigma_{y} \tau_{x y}^{2}-1=0$

The obtained failure surface of Page's tests is schematically illustrated in Fig. 6 in $\sigma_{x}-\sigma_{y}-\tau_{x y}$ space.

7.

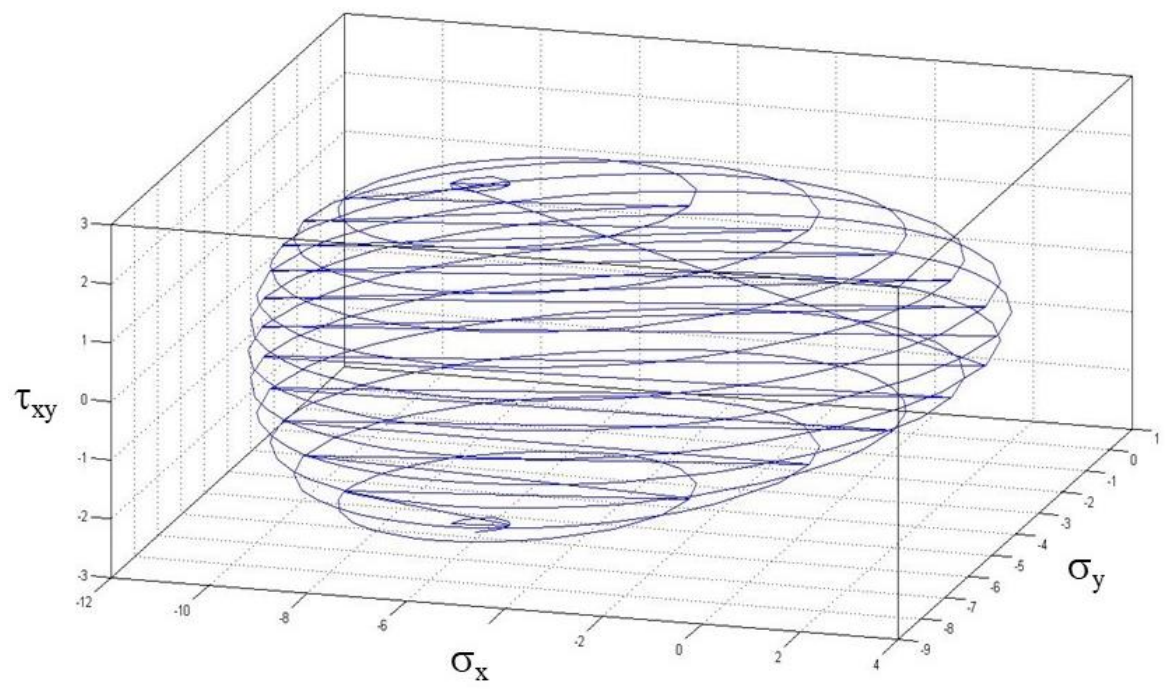

8. Figure 6 Failure surface $\left(\sigma_{x}-\sigma_{y}-\tau_{x y}\right.$ space $)$.

\subsection{Comments on the Results}

The results of different approaches are shown in Fig. 7 for the case of $\left(\sigma_{x}\right.$ and $\sigma_{y}$ plane $\left(\tau_{x y}=0\right)$ and in Fig. 8 for the case of $\left(\left(\sigma_{x}=\sigma_{y}\right)-\tau_{x y}\right)$. The proposed failure criterion gives better results considering the compatibility with Page results. As shown in the figure the proposed equation, using the 45 points, give better results than the other aproaches. In Page's experiments the maximum shear stress (ranges between 3.0 to 3.6 MPa and occurs at a normal stress $\left(\sigma_{\mathrm{x}}=\sigma_{\mathrm{y}} \approx 4.3 \mathrm{MPa}\right)$, Fig. 8 .

The equation obtained from the 45 points represents the test points better than Syrmakezis and Asteris equation (2001), Figs. 7 and 8. It is obvious that a closed surface depending on one equation is more efficient numerically than a surface consisting of two intersecting yield surfaces, Fig. 2. The closeness of the proposed surface to the experimental tests of Page, which is evident in Figs. 7-9 gives confidence in the proposed modeling of masonry walls. The cubic polynomial which resulted in a closed surface is crucial for applying continuum damage mechanics and the incremental approach needed to describe the orthotropic materials in the post-peak domain. 


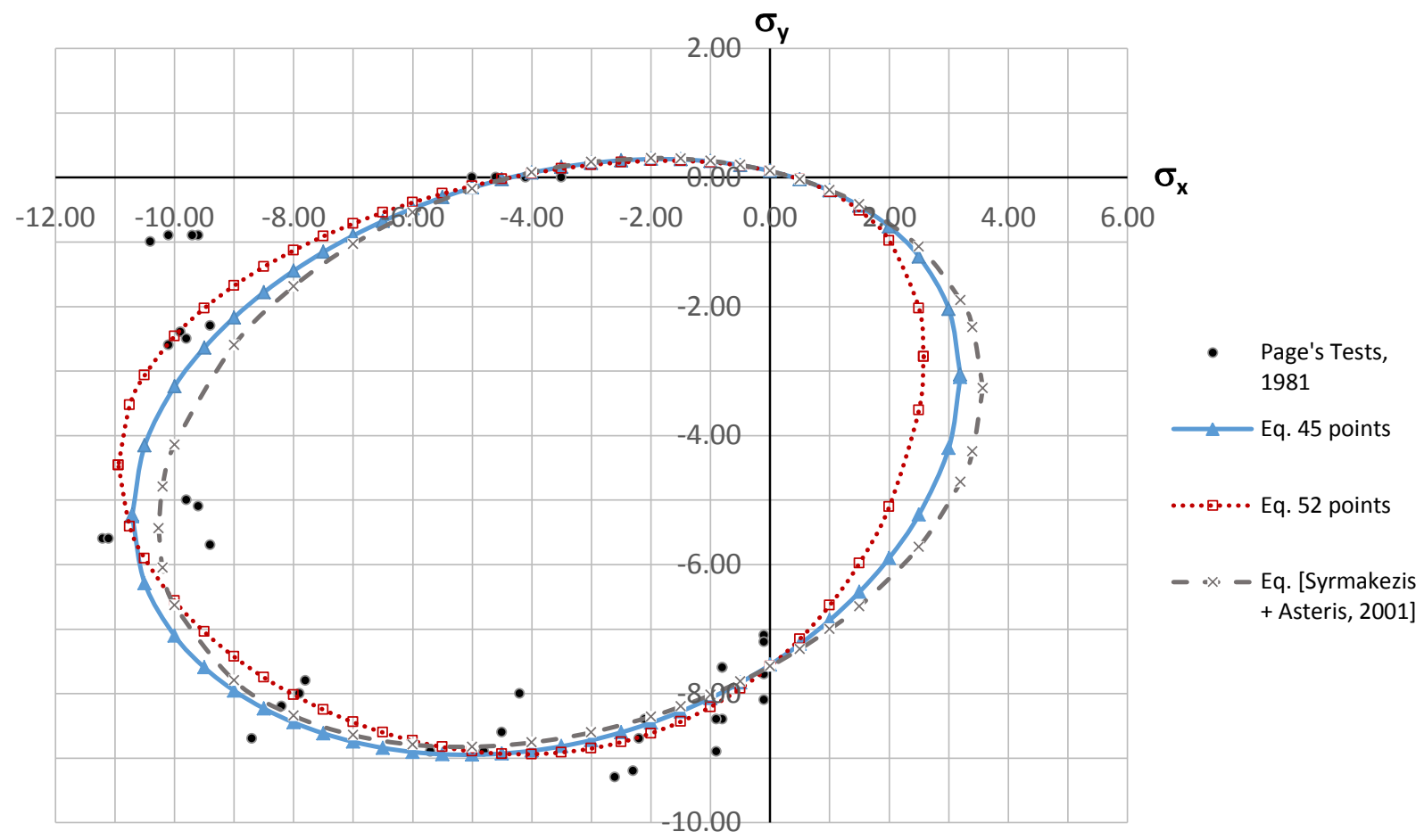

Figure 7 Plot at $\theta=0$ for the evaluated equations.

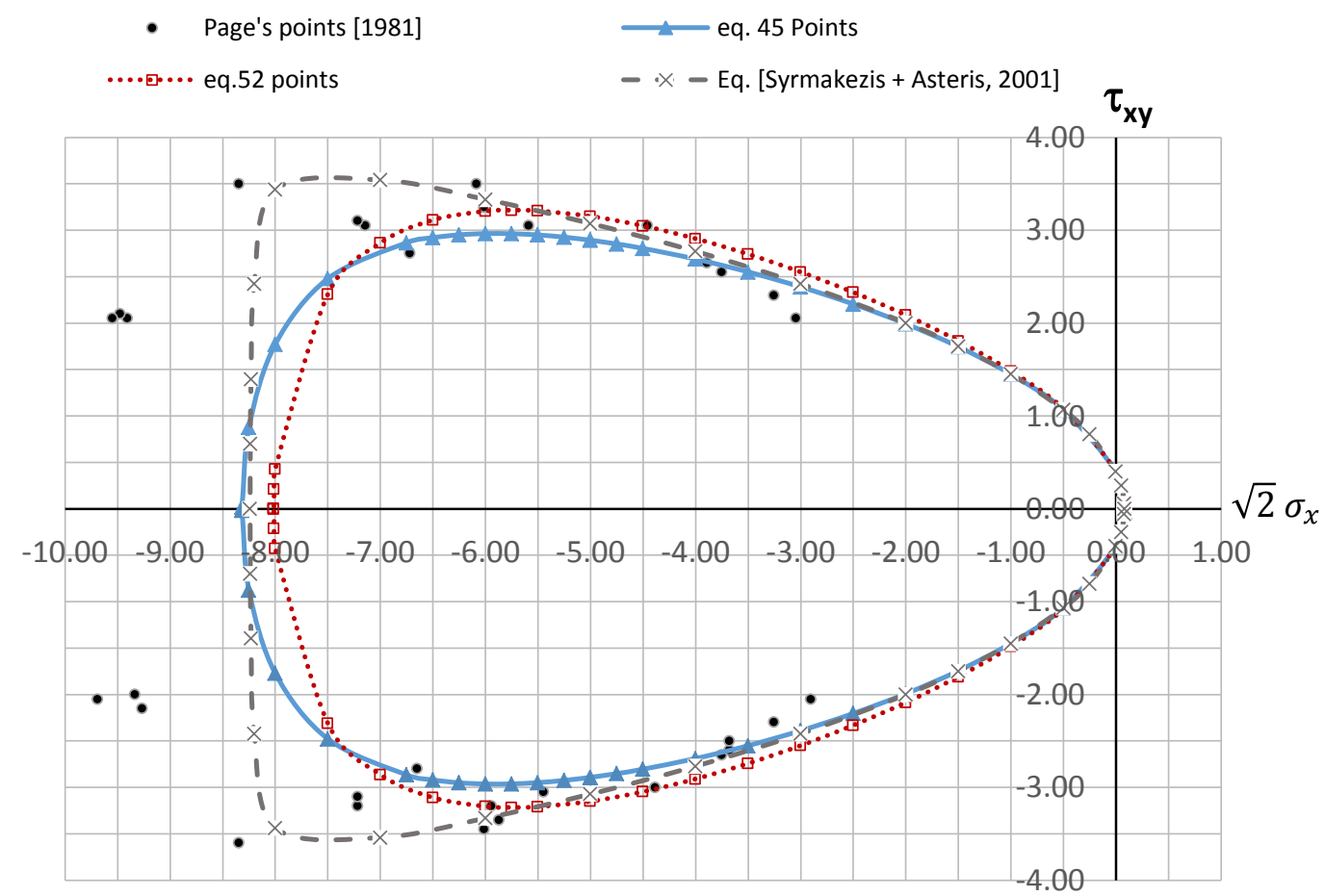

Figure $8\left(\sigma_{x}=\sigma_{y}\right)-\tau_{x y}$ plane for the different equations. 


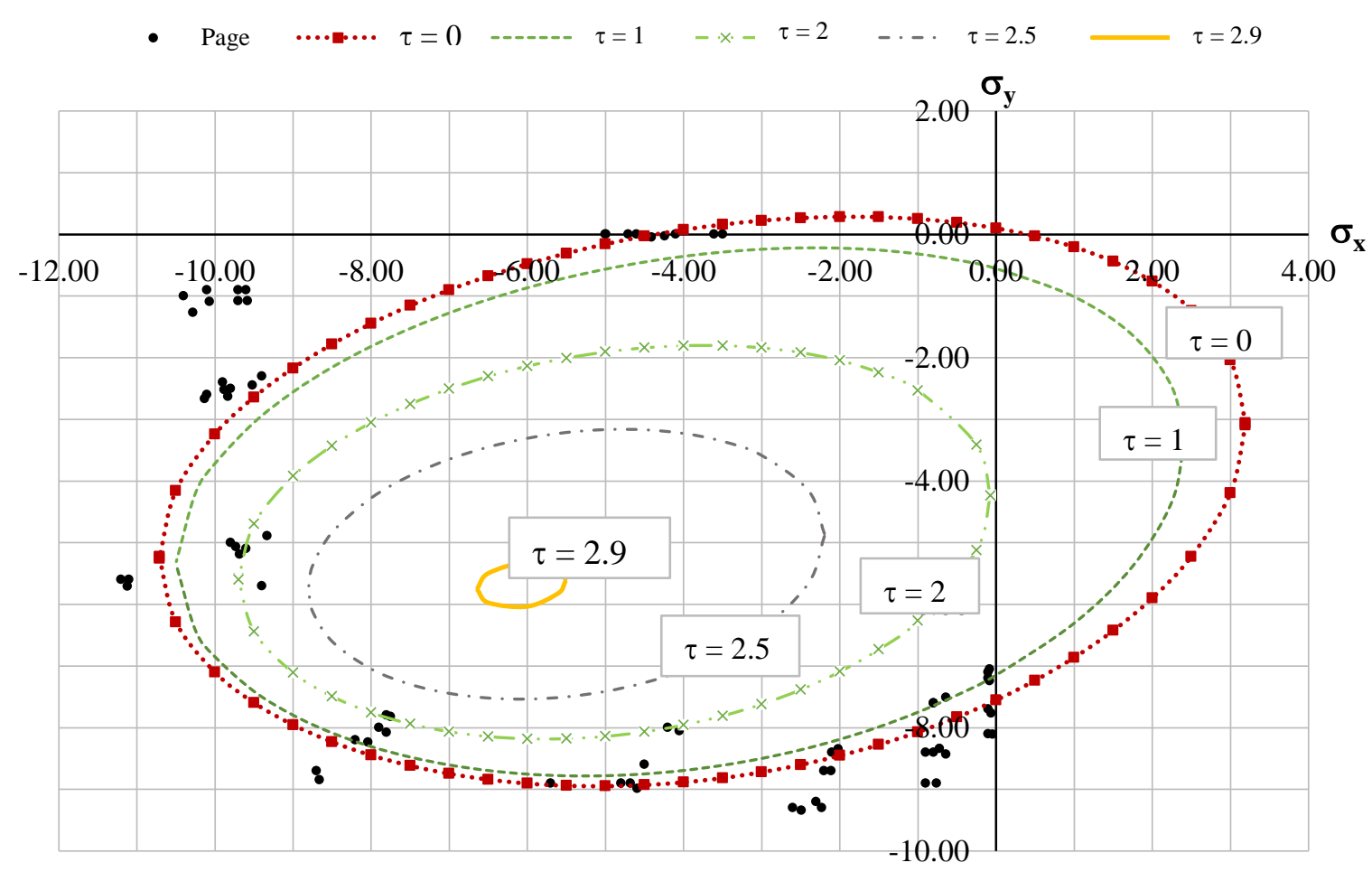

Figure 9 Regression of 45 Points at different shear levels, $\tau=$ variable.

\section{DAMAGED FAILURE SURFACE}

\subsection{Effect of Damage on Failure criteria}

For composite, homogenized and orthotropic materials, damage can be accurately represented by a second-order tensor with the principal directions aligned with the orthotropic directions (Barbero and Lonetti, 2001). The homogenized masonry panel represents a two dimensional plane stress problem. Hence, the two dimensional damage tensor $[D]$ is

$[D]=\left[\begin{array}{cc}d_{x} & 0 \\ 0 & d_{y}\end{array}\right]$

where the variables $d_{x}$ and $d_{y}$ designate damage in the $\mathrm{x}$ - and y-directions, respectively.

In order to account for damage the solution procedure has to be written in an incremental form. After introducing damage into the calculated failure criterion, Eq. (4), the peak value has to continuously be calculated according to the stress-state and damage at every solution increment. The line from the origin through the current stress state intersects the failure surface (the damaged failure surface, $\hat{g}$ ) in the peak stress values in both directions.

$$
\begin{aligned}
& \hat{g}=a_{1} \frac{\sigma_{x}}{\left(1-d_{x}\right)}+a_{2} \frac{\sigma_{y}}{\left(1-d_{y}\right)}+a_{3} \frac{\sigma_{x}^{2}}{\left(1-d_{x}\right)^{2}}+a_{4} \frac{\sigma_{y}^{2}}{\left(1-d_{y}\right)^{2}}+a_{5} \frac{\tau_{x y}^{2}}{\left(1-d_{x}\right)\left(1-d_{y}\right)}+ \\
& a_{6} \frac{\sigma_{x} \sigma_{y}}{\left(1-d_{x}\right)\left(1-d_{y}\right)}+a_{7} \frac{\sigma_{x} \sigma_{y}^{2}}{\left(1-d_{x}\right)\left(1-d_{y}\right)^{2}}+a_{8} \frac{\sigma_{x}^{2} \sigma_{y}}{\left(1-d_{x}\right)^{2}\left(1-d_{y}\right)}+
\end{aligned}
$$


$a_{9} \frac{\sigma_{x} \tau_{x y}^{2}}{\left(1-d_{x}\right)^{2}\left(1-d_{y}\right)}+a_{10} \frac{\sigma_{y} \tau_{x y}^{2}}{\left(1-d_{x}\right)\left(1-d_{y}\right)^{2}}-1=0$

Since the shear damage in a masonry panel is a stepped crack through the head and bed joints, the shear damage can be introduced by two components; one in the $\mathrm{x}$ direction and the other in the y-direction as in Eq. (9).

\subsection{Variation of Damage in the $x$ - and $y$-Directions}

At any biaxial stress state the strength can be calculated in the $\mathrm{x}$ - or $\mathrm{y}$-direction from the failure surface. Figures 10 and 11 show the biaxial effect on the strength with respect to the uniaxial strength. For instance, such effect on the ultimate strength in the y-direction is obvious in Fig. 10, upon comparing with the uniaxial strength. As for Fig. 11, the biaxial effect on the ultimate strength in the x-direction, is very significant. As can be seen from the results in Figs. 10 and 11, the biaxial effect varies in both directions which is very interesting in highlighting the orthotropic material characteristics of masonry walls.

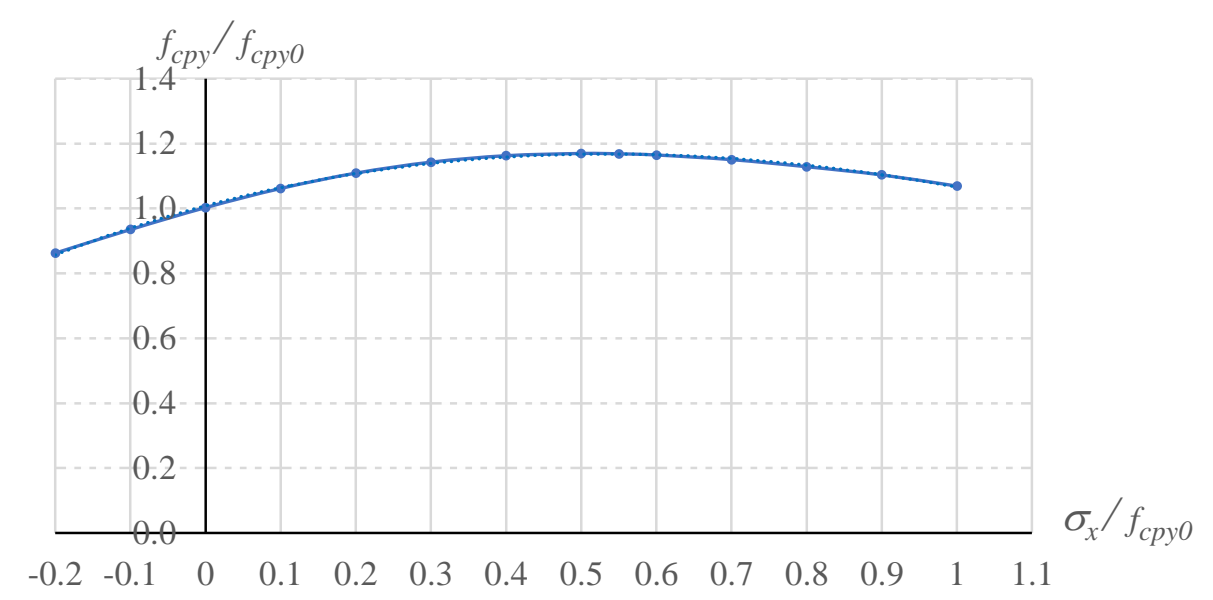

10. Figure 10 Biaxial effect on the strength in $y$ - direction w.r.t. uniaxial strength. 


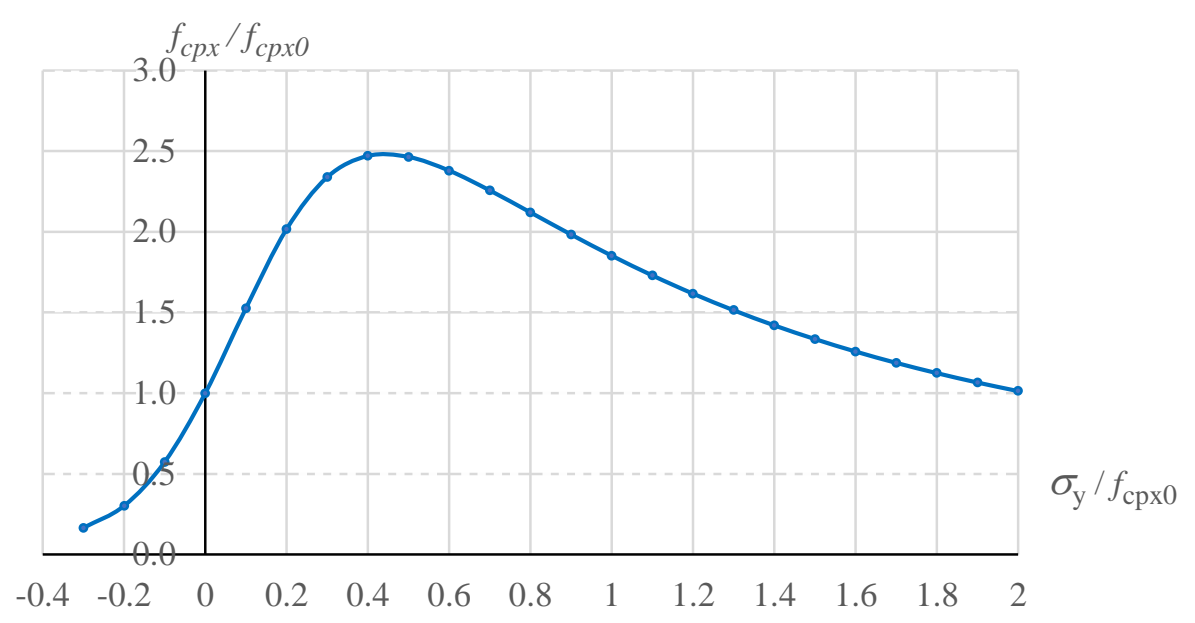

11. Figure 11 Biaxial effect on the strength in $\mathrm{x}$ - direction w.r.t. uniaxial strength.

Figures 12 to 14 show the failure surface for different levels of damage in the $\mathrm{x}$ - and $\mathrm{y}$-directions. Damage alters the failure surface in such a way that the peak stress is different for every increment. Therefore, it is crucial to recalculate the peak stress value for every increment based on the corresponding confinement and damage levels. This should be calculated using the current stress state of the material and the current failure envelope.

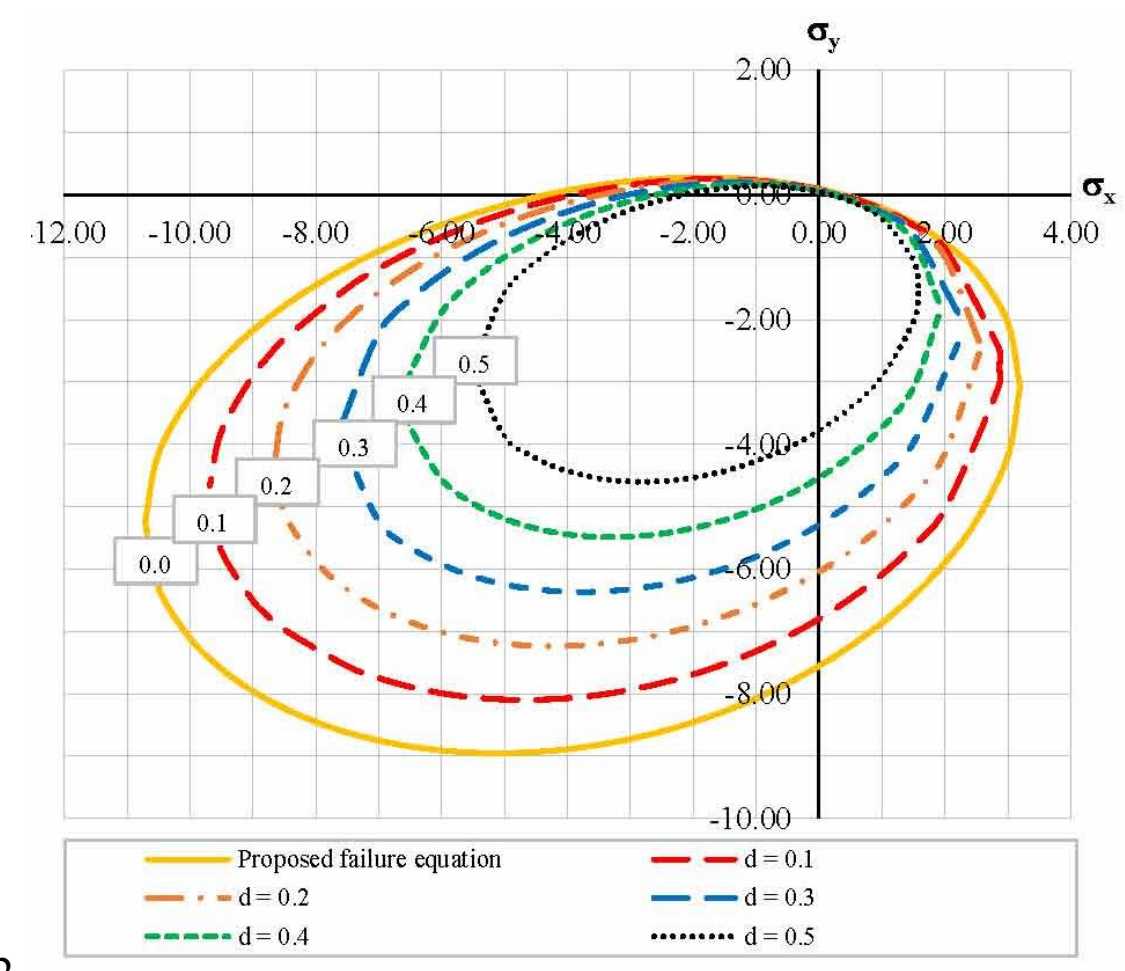

12.

13. Figure 12 Change of failure surface with damage $d_{x}=d_{y}$ (isotropic damage). 


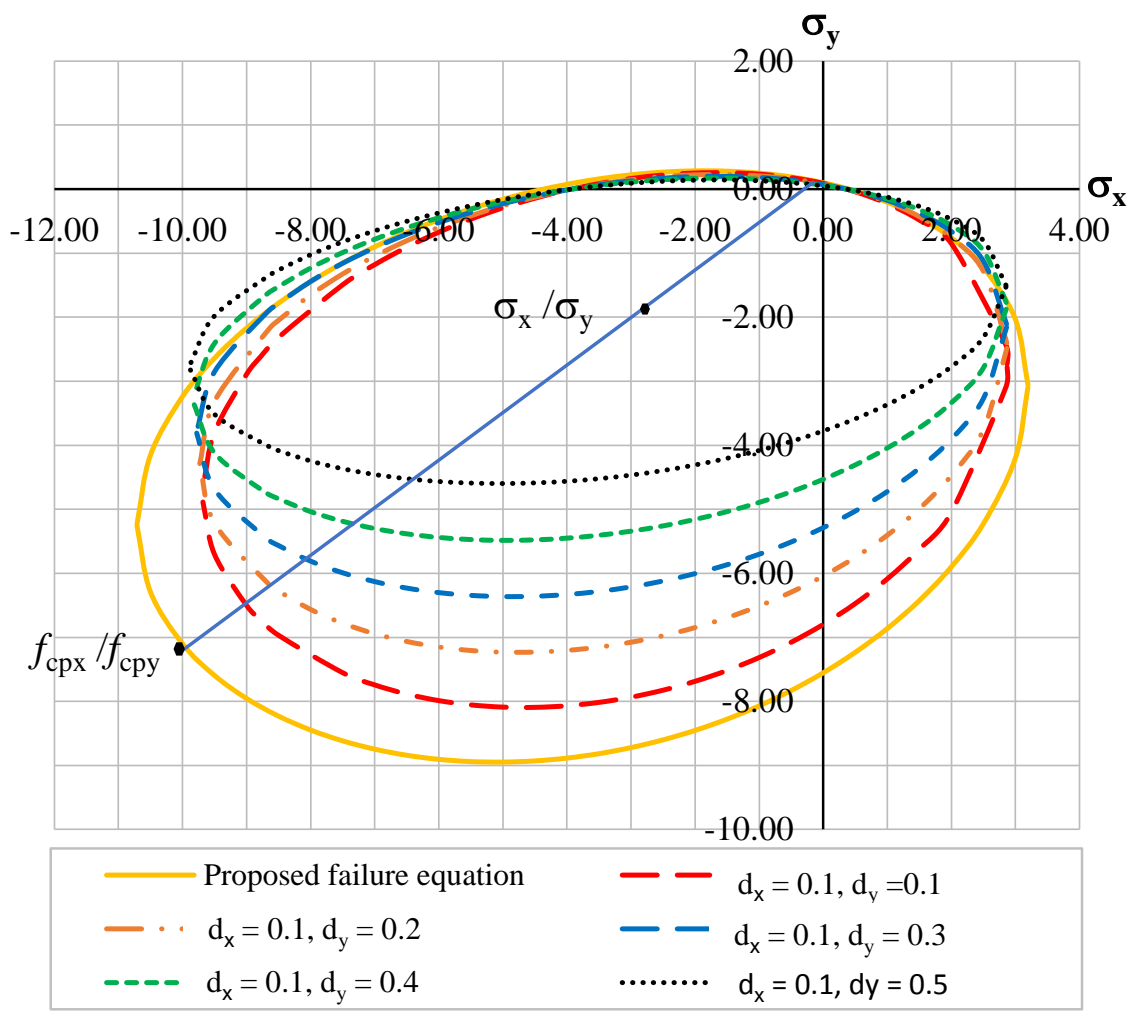

14. Figure 13 Change of failure surface with damage $d_{x}=0.1$ and $d_{y}$-variable.

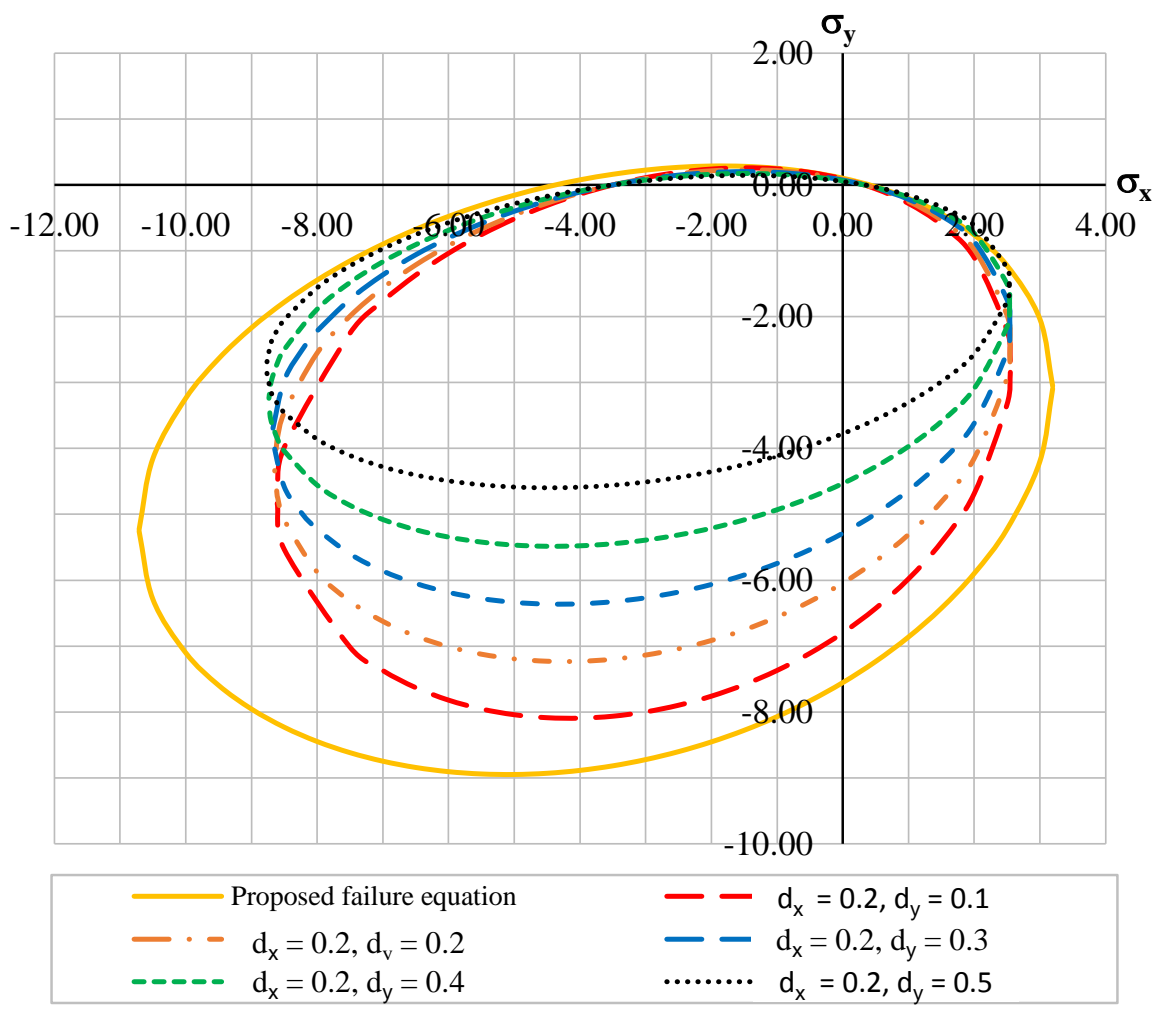

15. Figure 14 Change of failure surface with damage $d_{x}=0.2$ and $d_{y}$-variable. 


\section{CONCLUSIONS}

Sufficient experimental data and the proper choice of the test data are very important to find a suitable expression to model the failure surface of masonry. The third degree polynomial was found appropriate and efficient in describing the failure surface of masonry since it can account for the orthotropic behavior and the confinement effect. Introducing damage to the failure surface allows for correct modeling of the orthotropic material under damage. The method of energy equivalence describing damage has proven efficient in the numerical modeling and therefore it can be used in masonry wall modeling. The potential of the proposed failure surface in the numerical analysis is evident, especially when applying continuum damage mechanics and the homogenization technique.

\section{REFERENCES}

16. Asteris, P.G., "A simple heuristic algorithm to determine the set of closed surfaces of the cubic tensor Polynomial," The Open Applied Mathematics Journal, 2010, 4, 1-5.

17. Anthoine A., Derivation of the in-plane elastic characteristics of masonry through homogeneization theory, Int J Solids Struct 1995; 32(2):137-63.

18. Barbero, E. J., Lonetti P., "Damage model for composite defined in terms of available Data." Mechanics of composite Materials and Structures, 8(4): 299315, 2001.

19. Dhanasekar, M., Page, A. W. and Kleeman, P. W., "The failure of brick masonry under biaxial stress." Proc. Instn Civ. Engrs, Part 2, 79, June 1985, 295-313.

20. Hill, R., 1950. The Mathematical Theory of Plasticity, Oxford University Press, New York.

21. Lopez J., Oller S., Oñate E., Lubliner J., A homogeneous constitutive model for masonry, International Journal for Numerical Methods in Engineering, 1999, Volume 46, Issue 10, 1651-71.

22. Lourenco, P., B, "An orthotropic continuum model for the analysis of masonry structures." TNO building and construction research, report no. 95NM-R012, 1995.

23. Lourenco, P. B., "Experimental and numerical issues in the modeling of the mechanical behavior of masonry." Structural analysis of historical construction II, CIMNE, Barcelona, 1998.

24. Milani G., FE homogenized limit analysis model for masonry strengthened by near surface bed joint FRP bars. Compos Struct, 2010; 92(2): 330-8.

25. Milani G, Bucchi A., Kinematic FE homogenized limit analysis model for masonry curved structures strengthened by near surface mounted FRP bars. Compos Struct, 2010; 93(1):239-58.

26. Milani G, Milani E, Tralli A. Approximate limit analysis of full scale FRP reinforced masonry buildings through a 3D homogenized FE package. Compos Struct 2010; 92(4): 918-35. 
27. Page, A.W., "The biaxial compressive strength of brick masonry." Proc. Instn Civ. Engrs, Part 2, 71, Sept. 1981, 893-906.

28. Prager, W. (1959). An Introduction to Plasticity, Addison Wesley Publishing Co., Reading Mass.

29. Quinteros, R.D., Oller, S., and Nallim, L.G., "Nonlinear homogenization techniques to solve masonry structures problems," Composite Structures, 94, 2012, pp. 724-730.

30. Sacco, E., A nonlinear homogenization procedure for periodic masonry. Eur J Mech A/Solids 2009; 28: 209-22.

31. Samarasinghe, W., Page, A. W. Hendry, A. W., "The in plane failure of masonry- an overview." Seventh International Symposium on load bearing Brickwork, June 1980, Vol. 1, No. 2.

32. Suquet, P., "Approach by homogenization of some linear and nonlinear problems in Solid Mechanics". in J.P. Boehler (ed.) Comportement plastique des Solides anisotropes. Edition du CNRS. Paris, 1985, 77-117.

33. Syrmakezis, C. A. and Asteris, P. G., "Masonry failure criterion under biaxial stress state." Journal of Materials in Civil Engineering, Jan-Feb, 2001.

34. Tsai, S. W. and Wu, E. M., "A general theory of strength for anisotropic materials.” Journal of Composite Materials. vol. 5, Jan. 1971, pp. 58-80.

35. Zienkiewicz, O. C., Valliapan, S., and King, I. P., "Elasto-plastic solutions of engineering problems 'initial stress', finite element approach," International Journal for Numerical Methods in Engineering, 1, March 1969, pp. 75-100. 